PROBLEMS

OF EDUCATION

IN THE $21^{\text {st }}$ CENTURY

Volume 62, 2014

62

BYSTANDER IN THE CLASSROOM? THE ROLE OF FEELING-OF-BEING-CONCERNED IN THE PERCEPTION OF THE POSSIBILITY TO HELP UNRULY BEHAVING PUPILS AND ITS RELATION WITH SOCIAL COGNITIVE FLEXIBILITY

\author{
Aneta Mechi \\ University of Geneva, Geneva, Switzerland \\ E-mail: Aneta.Mechi@unige.ch
}

\begin{abstract}
With the aim of dealing with educational cross-domain problems that are likely to appear in each course regardless of the teaching domain, the teachers can either take the initiative to help or they can choose not to intervene. Despite the helpful recommendations to make all pupils participate (UNESCO) or no child left behind (NCLB in the United States), most teachers are unaware of their differential helping behavior when they are faced with an ambiguous or problematic educational situation. In line with the bystander effect literature and stereotype content model, the mechanism that underlies the decision of not helping is identified as the feeling that drives an individual to get into the given situation: the feeling of being concerned (FBC). FBC is supposed to redirect individuals away from hasty, biased conclusions and lead them to some distance from any information (i.e., social cognitive flexibility). It is hypothesized that the more one feels concerned by the situation, the more distance he or she tends to take based on the available information. In a current online survey, the participating teachers in training first gave their opinions about the proposed statements (i.e., the social cognitive flexibility measures), then they read one standardized scenario of the educational situation, and finally they responded to questions related to the perceived possibility of helping the pupils in the scenario. The quantitative results (according to ANOVA) show that the teachers with a high FBC report a higher perceived possibility to help and show a higher level of social cognitive flexibility compared to those with a low FBC. These results are supported by significant correlations and are discussed in terms of their implications for the teachers 'practice.
\end{abstract}

Key words: bystander effect, feeling-of-being-concerned, helping behavior, unruly behavior.

\title{
Introduction
}

The various generations of migrants and the recent progress of globalization and professional mobility have contributed to the formation of a heterogeneous school that needs adequate approaches with the aim to give all pupils the highest chance of success. The problems related to contact between the cultures have juxtaposed to those that existed before, such as unruly behavior, low performance or dropping out of school and challenges the competence approaches. In this changing climate, it becomes necessary to develop new approaches and provide teachers with useful tools to enable them to face different educational situations.

All the teachers may be faced in their careers with the problems of unruly behavior, lack of motivation, or drop in performance and, as an individual, have a biased perception and interpretation of these situations. Every teacher can tend to explain these situations using in- 
formation such as social-cultural background or immigrant status. Indeed, in a study by Darley and Gross (1983), the individuals being invited to assess an ambiguous performance implicitly based their assessment on the social-economic background information. Chryssochoou, Picard, and Pronine (1998) show the explanations of the students' success or failure varying according to their first names (foreign/another culture connotation) and their fathers' professions. Knowing the category of the target, the individual faced with ambiguous performance tends to judge a person in terms of stereotypes, but also anticipates what could be expected from this person. Jones and McGillis (1976) have called this kind of anticipation the "category-based expectancies": the expectancies derive from the perceiver's knowledge of the target person's class, category, or reference group (...). From this knowledge, the perceiver can generate at least crude expectancies about attribute-effect linkages" (Jones \& McGillis, 1976, p. 393). Such expectations and judgments can lead to hasty conclusions and influence our behavior; for example, the intention of helping or perception of the possibility of helping. Fiske (2012) emphasizes the difference in helping according to the target's level of competence and warmth. Overestimation of both the characteristics of pupils (fundamental attribution error; Ross, 1977 known also as a correspondence bias; Smith \& Mackie, 2007) and the weight of cultural-immigrant background in the success or failure at school (ultimate attribution error, Pettigrew, 1979), makes it difficult to think in terms of a pupil's potential and perceived possibilities and to help every pupil regardless of his or her behavior when learning and in relations with others. Contrary to what one could think spontaneously, helping behavior does not always follow the social responsibility norm (helping those who are not able to care of themselves; Berkowitz, 1972). Contextual conditions influence considerably individual's behavior in these helping situations.

Problem of Research

\section{Bystander effect}

On March 13, 1964, Kitty Genovese was assaulted while nearly 38 neighbors were aware of the murder that was occurring in front of their houses and yet nobody rescued her or called the police. These witnesses' indifference was conceptualized as the bystander effect (BE; Latané \& Darley, 1968, 1970; Latané, Nida, \& Wilson, 1981), which posits that helping behavior decreases when the number of individuals increases. Stating it in another way, the more bystanders, the lower the probability that someone among them will help the victim. On October 21, 2011, L'Express announced the death of two-year old girl, who was hit by two vehicles. Wang Yue lay dying under the gaze of passersby. According to another source of information (People Daily, 10/21/2011), a video recorded by a surveillance camera reveals that 18 people passed by the dying girl for six minutes after the accident without coming to her assistance. The 19th passerby was an older woman who picked up garbage and she dragged Wang Yue's little body out of the way of vehicles and cried out for help. However, there are also the emergencies where somebody, one person from a crowd, decides to rescue the victim regardless of the personal dangers. In 2009, a passerby was murdered in a German train station by two 18 -year-olds after trying to help a child attacked by these boys. Several passersby witnessed the murder, but nobody decided to intervene, except one. Hence, the bystanders sometimes choose to intervene, but to what extent are they personally responsible to help?

\section{Helping in Juridical Terms, "Failure to Render Assistance to a Person in Danger"}

In Switzerland, Article 128 "Omission of lending assistance" of the penal code says as follows: "One who will not lend assistance to a person (...) in imminent danger of death (...) will be punished with a sentence of deprivation of liberty of at most three years or a pecuniary penalty." In France, the law mentions (1'art. 223-6[2]) that the person who refrains voluntarily from rendering assistance to somebody who is in danger will be punished with a sentence of 
Aneta MECHI. Bystander in the Classroom? The Role of Feeling-of-Being-Concerned in the Perception of the Possibility to Help Unruly Behaving Pupils and its Relation with Social Cognitive Flexibility

OF EDU

PROBLEMS

IN THE $21^{\text {st }}$ CENTURY

Volume 62,2014

64 five years of imprisonment and a fine of 75,000 Euros. To be accused, however, two conditions are needed: first, the victim has to be dying, and second, the help has to be possible. Certain states in the United States of America and in Canada have adopted a "Good Samaritan Act" whereby they do not punish the failure to render assistance, but they facilitate an intervention with the exoneration of all responsibility (nobody must help, but anyone who intervenes is not responsible for the death or the disability of the victim). Hence, if an individual is not required to help or is required to do so only when facing the danger of death, what are the factors that influence the decision to help or not to help and to intervene or not to intervene?

\section{Helping conditions}

It seems that some conditions reduce the strength of the bystander effect. Latané and Nida (1981) have examined occurrences of this phenomenon according to the different characteristics of bystander/emergency situation such as 1) attributes of the accident (rural/urban: higher BE in urban areas; Merrens, 1973); 2) conducted in laboratory or in the field; 3) the level of accident ambiguity (higher BE in the ambiguous situations; Solomon, Solomon \& Stone, 1978); and bystander/victim attributes such as the bystander's competence (lower BE in the case of competence; Bickman, 1971, van den Bos, Müller, \& van Bussel, 2009) or the victim's ethnicity (Gaertner, Dovidio, \& Johnson, 1982). Other examined aspects were the characteristics of other bystanders (friends/strangers: higher BE among strangers) and the level of communication with each other (lower BE in the case of communication; Latané \& Nida, 1981). Besides, the authors have identified the contexts of the bystander effect occurrences such as 1) the danger for all bystanders (Latané \& Darley, 1968), 2) the danger for the victim (Harris \& Robinson, 1973; Latané \& Darley, 1968), 3) villainous acts (steal money; Latané \& Elman, 1970; Howard \& Crano, 1974), and 4) non-emergency incidents like answering the door (Frieeman, 1974) or help with a broken car (Hurley \& Allen, 1974). Clark and Word (1974) emphasize the ambiguous characteristics of the situation as the most important factor in decreasing helping behavior.

Latané and Darley (1970) have proposed a five-step psychological process model that identifies the stages of bystanders' reasoning leading to an intervention or non-intervention decision. According to the authors, the individual needs first to 1) notice a critical situation, 2) construe the situation as an emergency, 3) develop a feeling of personal responsibility, 4) believe in having the necessary skills to intervene efficiently, and 5) make a conscious decision to help. The authors identified several mechanisms that might interfere with the completion of the five-step reasoning. One of them is diffusion of responsibility, which refers to the mode of thinking in terms of devised responsibility. When the individual is alone facing a critical situation, he/she is the only person and knows that if he/she will not help, then nobody else will do it. On the contrary, when many other people are present, they seem to be potentially able to help and responsibility becomes muddled (Schwartz \& Gotleib, 1980). This diffusion seems to be higher in cities with higher population densities since the rate of helping decreases in such areas (Levine, Martinez, Brase, \& Sorenson, 1994). Of course, there are norms that make helping appropriate or inappropriate (Smith \& Mackie, 2007).

On the one hand, the norm of social responsibility mentioned above posits that the people who are able to care of themselves should assist those who cannot (Berkowitz, 1972). On the other hand, an implicit norm is often given by the first person who decides to intervene in the critical situation thus implicitly defining the intervention as an appropriate behavior (Bandura, 1977; social learning theory). The decision to help is also linked to the judgment of deservingness: Whether he/she thinks that the victim deserves help (Caporael \& Brewer, 1991). In the occidental individualistic society, the expression of an internal explanation of behavior seems to be socially valued. Jellison and Green (1981) have conceptualized the norm of internality that was developed by Beauvois and Dubois (1988). Thinking that the victim "brought it on him/herself" decreases the probability of deservingness judgment and thus decreases helping 
(Reisenzein, 1986; Schmidt \& Weiner, 1988). Another norm that makes people unwilling to intervene is the norm offamily privacy, which considers that "that is family business" (Shotland \& Straw, 1976).

Nevertheless, the bystanders are not insensitive persons judging the victim. They are often hesitant and anxious about what is best to do: Behave inappropriately by helping or behave inappropriately by not helping (Smith \& Mackie, 2007). They are also afraid to make mistakes during intervention since they are being observed. This is a second mechanism that might interfere with the five-step reasoning process. Latané and Darley (1970) call it evaluation/apprehension (the fear of being judged). The third process refers to the implicit link that individuals make between their reactions and those of others' thinking (pluralistic ignorance; Miller \& McFarland, 1987) such that everyone thinks that no one else perceives the emergency (Latané \& Nida, 1981).

Thus, the bystanders choose to intervene or not to intervene according to conditions which facilitate occurrence of this phenomena or restrain it. But what is the mechanism underlying this decision?

\section{Feeling-of-being-concerned (FBC)}

Although the bystanders' competence is one of the factors increasing their helping behavior, their help seems to vary according to the characteristics of the person in need. The bystanders are more willing to help their kin (Kruger, 2003), in-group members, similar others, or those perceived as sharing similar values (Karabenick, Lerner, \& Beecher, 1973; Levine, Proser, Evans, \& Reicher, 2005; Penner, Dovidio, Piliavin, \& Schroeder, 2005; Stürmer, Snyder, \& Omoto, 2005). The witness is "external" to the accident or the problem. She or he is faced with the necessity to decide whether to be the situation or not and whether to contribute to the processes of resolution or not. Since the help is more often provided to the kin or in-group members regardless of bystanders' competence, the mechanism underlying the decision to help seems to be related to the feeling of being concerned (FBC) with the given situation that convinces a witness to "get involved in the situation." Prior to helping behavior, FBC is supposed to be influenced by the category or status of the person in need. Fiske et al.'s studies on the stereotype content model (Cuddy, Fiske, \& Glick, 2008) shed a new light on helping behaviour and its relation with the perceived competence and warmth of the person needed.

\section{Stereotype Content Model}

The stereotype content model (Cuddy, Fiske, \& Glick, 2008) posits that stereotypes of social groups (according to status) result from perceived social structure. Hence the individual's helping behavior differs according to the target's level of warmth and competence (Fiske, 2012). The combinations of positions on the two dimensions of social perception (low and high warmth/high and low competence) and emotion associated to the social groups on these positions - 1) pity (high warmth but low competence), 2) pride (high competence and high warmth), 3) envy (high competence but low warmth, and 4) disgust (low competence and low warmth) - encourage different kinds of behavior such as helping (in the case of low competence but high level of warmth and in the case of high competence and high warmth) and harm (in the case of high competence but low warmth and in the case of low competence and low warmth). 
Aneta MECHI. Bystander in the Classroom? The Role of Feeling-of-Being-Concerned in the Perception of the Possibility to Help Unruly Behaving Pupils and its Relation with Social Cognitive Flexibility

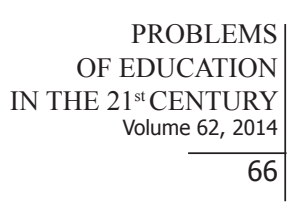

\section{Helping Behavior in Teaching}

For the teachers, the cross-domain educational situations (an unruly behavior, a drop in performance, or a lack of motivation) are often ambiguous and difficult to understand or resolve, because they are beyond the specific domain concerns per se. Thus, research on the source of the problem means the investigation of circumstances (situations during different lessons; during the classes of different teachers; according to different periods of the day, week, month or year; different rooms in which the classes are given, including group dynamics; and intra- and inter-personal relations) with the aim to find what could improve the given pupil's performance. This investigation has a cognitive cost and demands an attentional resource. For this reason, the teacher (like a witness of someone's sudden weakness) makes the decision to "get involved," to attempt to resolve the problem, yet this seems to be difficult. Thus, the diffusion of responsibility can be a mechanism that prevents the teacher from feeling-of-beingconcerned. Indeed, although at first glance the teacher seems to be alone with his or her class because the problem is cross-domain, he or she can feel an affiliation to the implicit group of "teachers of this class" or, more broadly, "group of specialists," who are supposed to help the pupils to the same extent.

Different institutions make recommendations (i.e., UNESCO advocates making all pupils participate) and acts for better education. For example, in 2001, the Unites States implemented The No Child Left Behind Act that is designed to identify "schools that are consistently failing to serve poor and minority students - and to instigate school-based and systemic remedies so that all students are provided with access to a high-quality, standard-based education" (Balfanz, Legters, West, \& Weber, 2007, p. 559). Despite the different kinds of recommendations, the teachers do not seem to be personally required to understand and resolve the pupils' problems, especially those not directly linked to the learning dimension (e.g., problems with pairs, ostracism, comparisons, identity dynamics, etc.). Nevertheless, they seem to suffer burnout and depression from a lack of motivation, disinterest among pupils, inappropriate behavior, or from diversity (Tatar \& Horenczyk, 2003).

The research on helping behavior emphasizes the importance of the characteristics of the person in need (status, social category, in- or out-group member) when it comes to the helping behavior of the witness. The educational situations are analogous to those studied in the bystander effect: Teachers are often external to the situation (weak performance, aggressive or unruly behavior, and drop in performance), but if they take the initiative and decide to get involved, they can decrease the pain of the pupil in need (modify the seating plan, feed-back, verbal and non-verbal interactions with pupils, the mode of classwork, the form of evaluation and the form of sanction). This decision to get involved, which causes the teachers to ask, "What can I change with the aim to improve the given pupil's learning and well-being?" could drive them to reflect more in depth on the situation and thus take some distance from any information shaping their expectations and judgments (known as social cognitive flexibility; Mechi, 2012). Hence, it is hypothesized that the more one feels concerned by a situation, the more likely he or she will put into question some evidence.

In order to test the relationship between $\mathrm{FBC}$ and $\mathrm{SCF}$ and the perceived possibility of helping, the unruly-behaving pupil scenario was drawn up (this includes chatting during the lesson, the use of swear words, and leaving the class without permission), which is supposed to create less warmth in the teacher and thus lower his/her helping behavior. It was hypothesized that perceived possibility to help should be higher among teachers with a high FBC. 


\section{Methodology of Research}

$\mid$\begin{tabular}{l} 
PROBLEMS \\
OF EDUCATION \\
IN THE 21 $1^{\text {st }}$ CENTURY \\
Volume 62, 2014 \\
\hline 67
\end{tabular}

General Background of Research

In this study, pre-service teachers were invited to participate in the online survey, which was presented as a way to improve the training course. The participation was anonymous and free. The participants were asked to give their opinion about several general affirmations about pupils. After that, they were invited to read a scenario (a standardized educational situation described by a secondary teacher in training) and give their opinion about the helping possibility. The link to the questionnaire was available for one week (from the day of training when the invitation to the survey was announced to the next classes when the participants had received acknowledgments).

\section{Sample of Research}

The sample consisted of 174 teachers in training (women=103, men=71, mean age $=32.5$ ) in Geneva, all of whom were enrolled in a university teacher training program. Sixteen participants did not respond to the survey during the assigned time: Since the survey was presented as a way to improve the training, the availability of the link was extended for the remaining persons, but their answers were removed from analysis. FBC is a new concept and its test was conducted for the first time; hence, its reliability cannot be confirmed yet. To guarantee the trustworthiness of data, each participant was provided with her/his own personal link. The sample size was determined by the number of participants in teacher training in a given year.

\section{Instrument and Procedures}

The teachers in training were invited to complete a standardized online questionnaire. It was presented as a poll that would allow improvements in the contents of the training for years to come.

First, the participants were requested to indicate the degree of their agreement or disagreement with the claims related to their measure of social cognitive flexibility. Then, the participants were requested to read a scenario (see Table 1) with an educational situation concerning pupils' behavior and to indicate the degree of their agreement or disagreement with the statements related to this situation (FBC and perceived possibility to help this "scenario pupil”).

\section{Table 1. Scenario.}

\footnotetext{
In a class, the teacher asked the students to perform an individual exercise, stating that it required a silent attitude from the students. Despite this statement, one pupil continued to speak loudly with neighbors. The teacher then moves to this pupil and asks if she had a question. The answer was, "No, I don't." This prompted the teacher to clarify that there was therefore no reason to talk. At that time, the pupil said that she is "fed up with this school" and that anyway, she does not want to do this exercise. The teacher remained at her side and waited until she began to work. At that time, another pupil raised his hand and the teacher moved to answer the question. Once the teacher turned her back, the pupil resumed speaking with her neighbors, laughing aloud.

Then the teacher turned again toward the pupil and asked her if it would be possible to calm down. After that, the pupil showed her displeasure by saying, "But I am calm, b... h... (bloody hell). I'm fed up with this school and this course! Anyway, it is completely useless what is done here." All eyes are now focused on the teacher....
} 
Aneta MECHI. Bystander in the Classroom? The Role of Feeling-of-Being-Concerned in the Perception of the Possibility to Help Unruly Behaving Pupils and its Relation with Social Cognitive Flexibility

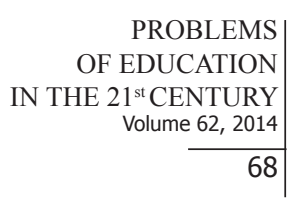

Independent variable

Feeling-of-being-concerned measured by the extent to which they think it is their role to resolve educational problematic situations associated with both the performance and the behavior in the classroom (Example: "As regards the problems related to the discipline, they must be resolved only by experts, such as psychologist or school adviser, etc." and "The role of the teacher should not go beyond the transmission of knowledge."). This variable was measured by a scale from 1 to $6(1=$ strongly disagree, $6=$ strongly agree $)$.

Dependent variable

Social cognitive flexibility is the distance participants take from the category- or traitbased information (background status, capacity, other teachers' opinions about the pupil) as a potential indicator of his/her behavior or his/her school performance. This variable was measured by the questions such as "Pupils performance reflects their capacities," "When the teacher's colleagues are agreeing about the pupil's class attitude, this opinion is right," "Pupils' performance reflects their social background," "Good pupils always have very good results," "Pupils' class attitude reflects their personality traits," "Problematic pupils always behave with a lack of discipline," "When the teacher's colleagues are agreeing about the pupil's performance, this opinion is right," "Problematic pupils usually come from a disadvantaged background."

The answers to the questions relating to these aspects was measured by the scale from 1 to $6(1=$ not at all, $6=$ strongly agree $)$. The SCF score has been reversed in order to assign the maximal level to the flexible answers and minimal level to the lack of distance from stereotypical statements.

Perceived possibility to help is the extent to which the participants consider helping a "scenario pupil" if possible. This variable was measured on a scale from 1 to 6 (1=absolutely impossible, $6=$ absolutely possible).

Hypotheses

H1: The teachers with a high $F B C$ would have a higher level of flexibility than those with a lower $F B C$.

H2: The teachers with a high $F B C$ would perceive a greater possibility to help than those with a lower $F B C$.

Questions related to FBC have been grouped according to the index of Cronbach's $\alpha$ (Cronbach's $\alpha=71$ ), which has been used also to calculate social cognitive flexibility variable (Cronbach's $\alpha=79$ ).

The variables associated with flexibility competence have been analyzed as dependent measures with the analysis of variance (ANOVA) and tested in terms of correlations.

\section{Results of Research}

Feeling-of-being-concerned, social cognitive flexibility and perceived possibility to help

The results provide an empirical support for the hypothesis concerning the impact of FBC on the social cognitive flexibility $\left(F(8,165)=4.78, p<0.00, \eta^{2}=0.19\right)$. The means and standard deviation are provided in Table 2. The one-way ANOVA was conducted to analyze the relation between FBC and perceived possibility to help an unruly behaving pupil from the 
Aneta MECHI. Bystander in the Classroom? The Role of Feeling-of-Being-Concerned in the Perception of the Possibility to Help Unruly Behaving Pupils and its Relation with Social Cognitive Flexibility

scenario used in the survey. In the global point of view, the results provide an empirical support to the assumptions regarding the effect of $\mathrm{FBC}$ on the perceived possibility to help $\mathrm{F}(8,165)$

$=3.29, \mathrm{p}<0.00, \eta^{2}=0.14$. The FBC seems to influence the participants' decision whether the help is possible or not and to what extent. The means and standard deviations are provided in Table 2.

Table 2. Means and standard deviation for $F B C$, social cognitive flexibility, and perceived possibility to help.

\begin{tabular}{llll}
\hline & FBC & SCF & Perceived possibility to help \\
\hline Mean & 5.11 & 4.43 & 4.47 \\
\hline Standard Deviation & 0.99 & 0.75 & 1.02 \\
\hline
\end{tabular}

The impact of the FBC on the SCF and the perceived possibility to help was also analyzed in terms of correlations and the results show that the relations between these variables are supported by significant correlations $(r=39, \mathrm{p}<0.00)$ for the relation between FBC and SCF and $\mathrm{r}=27, \mathrm{p}<0.00$ for the correlation between FBC and perceived possibility to help). The social cognitive flexibility is also positively related to the perceived possibility to help ( $\mathrm{r}=24$, $\mathrm{p}<0.002$ ).

Table 3. Correlations between the FBC, the social cognitive flexibility and perceived possibility to help the scenario pupil.

\begin{tabular}{llll}
\hline & FBC & SCF & Perceived possibility to help \\
\hline FBC & & \\
\hline \multirow{3}{*}{ SCF } & $0.385^{* \star}$ & \\
& 0.000 & \\
\hline \multirow{2}{*}{ Perceived possibility to help } & $0.268^{* *}$ & 0.000 & $0.236^{* *}$ \\
& 174 & 0.002 \\
\hline
\end{tabular}

The FBC seems to be positively correlated with both social cognitive flexibility and perception of the possibility of help.

\section{Discussion}

The results show that $\mathrm{FBC}$ seems to play a considerable role in both the perception of the possibility of helping and an increase in social cognitive flexibility. Indeed, those teachers in training who considered teaching as something more than the simple transmission of knowledge and who did not admit that "the problems related to the discipline must be resolved only by experts" seem less likely to hold stereotypical assumptions about pupil warmth and competence. They appear to be sceptical toward the category-based information. For them, the relation between the pupil's group, category, or reputation is not the only reason per se for their behavior or performance. The distance from stereotypical assumptions could mean they feel the need for extra information, observation, and inquiry to be able to say more about somebody's competence or warmth. Ongoing studies analyze the role of a feeling-of-being-concerned in cross-domain educational situations on the basis of real-life situations and analyze the factors 
Aneta MECHI. Bystander in the Classroom? The Role of Feeling-of-Being-Concerned in the Perception of the Possibility to Help Unruly Behaving Pupils and its Relation with Social Cognitive Flexibility

PROBLEMS

OF EDUCATION

IN THE $21^{\text {st }}$ CENTURY

Volume 62, 2014

70

that play a role in the development of SCF competence in order to stress these aspects in the training program through exercises or illustrations. Further studies will analyze in more depth (using mixed methods) the role of SCF competence in the promotion of inclusive action and the prevention of dropout.

Another finding of the current study is the significant influence of FBC on the perceived possibility to help. More particularly, teachers who believe they can resolve problems related to unruly behavior and those for whom teaching means more than the transmission of concepts appear more able to easily see the possibility of the modification of the problematic situation displayed in the scenario. For them, the pupil who is behaving inappropriately is not seen in a long-lasting manner, but rather, from a situational perspective, which sees the problem as modifiable. This is a very important aspect, especially since research into the helping behavior, as theorized by Cuddy, Fiske, and Glick (2008), shows that the person perceived as not warm is more often the target of harm. FBC seems to be the key to increasing helping people who are perceived as not warm. Specifically, in educational settings, even a one-time helping intervention can create a new situation in the given pupil's school career.

On the other hand, the difference in perception of helping possibilities between teachers with high and low FBC means that they have more room to maneuver in their daily practice. It is probably a matter of the awareness of what might be done to arouse the pupil's potential, both in the classroom and in the staff room (in formal and informal communication). The awareness of the extent of maneuver can be increased in a teacher's training in cross-domain competence, such as social cognitive flexibility, which provides teachers with several tools, and reduces uncertainty and random attempts to resolve the problematic educational situations

Although FBC has been conceptually defined, it needs more tests to analyze more precisely its relationship with SCF and perceived possibility to help in its most developed version. The relationship between FBC and inclusive action also needs to be analyzed. The results obtained in several studies are similar, but the measures need to be validated.

\section{Conclusions}

Teachers, like most of people, are more likely to spontaneously help likeable individuals, regardless of their competence, whereas they will often become bystanders when faced with an ambiguous or/and problematic situation, including that of an unlikeable pupil. This attitude seems to be facilitated by the multiplicity of professions (psychology experts, career counselors, social workers, deans of the given school level, and so forth), which risks creating a diffusion of responsibility (i.e. "I am not the only person facing a given pupil or class"). In the case of a troubling incident, they have the opportunity to pass on difficulties to the dean and will often use this option automatically, without trying non-coercive sanctions or solutions. The ultimate goal seems to be that of law enforcement rather than the participation of all pupils (a UNESCO and NCLB recommendation). There are many analyses of the NCLB implementation and the findings are somewhat confusing (Balfanz, Legters, West, \& Weber, 2007). On the one hand, it is depicted as undermining teachers' morale and intent to remain in the profession (media accounts: Hefling, 2012, Toppo, 2007, academic reports: Deniston \& Gerrity, 2010; Hill \& Barth, 2004) while, on the other hand, it has a surprisingly positive effect on teachers' job satisfaction and commitment to the profession (Grissom, Nicholson-Crotty \& Harrington, 2014).

FBC may be a part of the answer. Indeed, since NCLB remains a recommendation, it seems to be in opposition to the available norms, such as the norm of internality or family business mentioned above. Both accentuate the pupil's responsibility in their school career and risk restraining FBC and magnifying the bystander effect among teachers who encounter unlikeable or unruly-behaving grade-schoolers. Moreover, the attribution bias, a fundamental and ultimate error, can pertain in the teacher's conception not only of dispositional qualities, but also of factors like cultural and social status. These elements make teachers believe they are faced with a recommendation that is considered impossible to attain. The FBC and SCF development could 
be an alternative way to increase the participation of all pupils based on the teachers' own firm conviction. Thus, the teachers could put their cognitive resources to use in their room of maneuver instead of reflecting on the relevance of the governmental recommendation.

Of course teachers are not personally required to understand the situation of pupil in need and modify it. Nevertheless, if they decide to get involved and manage to resolve the problem, both pupil and teacher benefit of this success. Former in terms of perceived potential and latter in terms of perceived competence, job satisfaction and learning climate.

\section{References}

Bandura, A. (1977). Social learning theory. Englewood Cliffs, NJ: Prentice Hall.

Balfanz, R., Legters, N., West, T. C., \& Weber, L. M. (2007). Are NCLB's measures, incentives, and improvement strategies the right ones for the nation's low-performing high schools? American Educational Research Journal, 44 (3), 559-593.

Beauvois, J. L., \& Dubois, N. (1988). The norm of internality in the explanation of psychological events. European Journal of Social Psychology, 18, 299-316.

Berkowitz, L. (1972). Social norms, feelings, and other factors affecting helping behavior and altruism. In L. Berkowitz (Ed.), Advances in experimental social psychology (Vol. 6, pp. 63-108). New York: Academic Press.

Bickman, L. (1971). The effect of another bystander's ability to help on bystander intervention in an emergency. Journal of Experimental Social Psychology, 7, 367-379.

Caporael, L. R., \& Brewer, M. B. (1991). Reviving evolutionary psychology: Biology meets society. Journal of Social Issues, 47 (3), 187-195.

Chryssochoou, X., Picard, M., \& Pronine, M. (1998). Explications de l'échec scolaire. Les théories implicites des ensei-gnants selon l'origine sociale et culturelle de l'élève. Psychologie et éducation, 32, 43-59.

Clark, R. D., \& Word, L. E. (1972). Why don’t bystanders help? Because of ambiguity. Journal of Personality and Social Psychology, 24, 392-400.

Cuddy, A. J. C., Fiske, S. T., \& Glick, P. (2008). Warmth and competence as universal dimensions of social perception: The Stereotype Content Model and the BIAS Map. In M. P. Zanna (Ed.), Advances in Experimental Social Psychology (Vol. 40, pp. 61-149). New York: Academic Press.

Darley, J. M., \& Gross, P. H. (1983). A hypothesis-confirming bias in labeling effects. Journal of Personality and Social Psychology, 44 (1), 20-33.

Deniston, R. D., \& Gerrity, K. W. (2010). Elementary school teachers' perceptions of No Child Left Behind and its effects on morale. Scholarly Partnership, 5 (2), Article 4.

Fiske, S. T. (2012). The continuum model and the stereotype content model. In P.A.M. Van Lange, A.W. Kruglanski and E. T. Higgins (Eds). Handbook of theories of Social Psychology (Vol. 1, pp. 267288). London: SAGE Publications Ltd.

Gaertner, S. L., Dovidio, J. F., \& Johnson, G. (1982). Race of victim, non-responsive bystanders, and helping behavior. Journal of Social Psychology, 117, 69-77.

Grissom, Nicholson-Crotty, \& Harrington, (2014). Estimating the effects of no child left behind on teachers' work environments and job attitudes. Educational Evaluation and Policy Analysis, 20 (10), $1-20$.

Harris, V. A., \& Robinson, C. E. (1973). Bystander intervention: Group size and victim status. Bulletin of the Psychognomic Society, 2, 8-10.

Hefling, K. (2012, January 7). Education law's promise falls short after 10 years. Associated Press. Retrieved from http://news.yahoo.com/education-laws-promise-falls-short-10-years-135106148. html

Hill, D. M., \& Barth, M. (2004). NCLB and teacher retention: Who will turn out the lights? Education and the Law, 16, 173-181.

Howard, W., \& Crano, W. D. (1974). Effects of sex, conversation, location, and size of observer group on bystander intervention in a high risk situation. Sociometry, 37, 491-507.

Hurley, D., \& Allen, B. P. (1974). The effect of the number of people present in a non emergency situation. Journal of Social Psychology, 92, 27-29.

Jellison, J., M., Green, J. (1981). A self-presentation approach to the fundamental attribution error: the norm of internality. Journal of Personality and Social Psychology, 40, 643-649. 
Aneta MECHI. Bystander in the Classroom? The Role of Feeling-of-Being-Concerned in the Perception of the Possibility to Help Unruly Behaving Pupils and its Relation with Social Cognitive Flexibility

PROBLEMS

OF EDUCATION

IN THE $21^{\text {st }}$ CENTURY

Volume 62, 2014

Jones, E. E., McGillis, D. (1976). Correspondence inferences and the attribution cube: A comparative reappraisal. In John H. Harvey, William J. Ickes, and Robert F. Kidd, (Eds.), New Directions in Attribution Research (Vol. 1, pp. 389-420). Hillsdale, NJ: Erlbaum.

Karabenick, S. A., Lerner, R. M., \& Beecher, M. D. (1973). Relation of political affiliation to helping behavior on Election Day, November 7, 1972. Journal of Social Psychology, 91, 223-227.

Kruger, D. J. (2003). Evolution and altruism: Combining psychological mediators with naturally selected tendencies. Evolution and Human Behavior, 24, 118-125.

Latané, B., \& Darley, J. M. (1968). Group inhibition of bystander intervention in emergencies. Journal of Personality and Social Psychology, 10, 215-221.

Latané, B., \& Darley, J. M. (1970). The unresponsive bystander: why doesn't he help? New York: Appleton Century Crofts.

Latané, B., \& Elman, D. (1970). The hand in the till. In B. Latané and J.M. Darley (Eds). The unresponsive bystander: Why doesn't he help? New York: Appleton-Century-Crofts.

Latané, B., \& Nida, S. A. (1981). Ten years of research on group size and helping. Psychological Bulletin, 89, 308-324.

Levine, M., Prosser, A., Evans, D., \& Reicher, S. (2005). Identity and emergency intervention: How social group membership and inclusiveness of group boundaries shape helping behavior. Personality and Social Psychology Bulletin, 31, 443-453.

Levine, R. V., Martinez, T. S., Brase, G., \& Sorenson, K. (1994). Helping in 36 U.S. cities. Journal of Personality and Social Psychology, 67, 69-82.

Mechi, A. (2012). Unfreezing school reputations: the role of social cognitive flexibility. Problems of Education in $21^{\text {st }}$ Century, 40, 114-121.

Merrens, M. R. (1973). Nonemergency helping behavior in various sized communities. Journal of Social Psychology, 90, 327-328.

Miller, D. T., \& McFarland, C. (1987). Pluralistic ignorance: When similarity is interpreted as dissimilarity. Journal of Personality and Social Psychology, 53, 298-305.

Penner, L. A., Dovidio, J. F., Piliavin, J. A., \& Schroeder, D. A. (2005). Prosocial behavior: Multilevel perspectives. Annual Review of Psychology, 56, 365-392.

Pettigrew, T. F. (1979). The ultimate attribution error: Extending Allport's cognitive analysis of prejudice. Personality and Social Psychology Bulletin, 5, 461-476.

Reisenzein, R. (1986). A structural equation analysis of Weiner's attribution-affect model of helping behavior. Journal of Personality and Social Psychology, 50, 1123-1133.

Ross, L. (1977). The intuitive psychologist and his shortcomings: Distortions in the attribution process. In L. Bercovitz (Ed.), Advances in experimental social psychology (Vol. 10, pp. 174-221). New York: Academic Press.

Schmidt, G., \& Weiner, B. (1988). An attribution-affect-action theory of behavior: Replications of judgments of help-giving. Personality and Social Psychology Bulletin, 14, 610-621.

Schwartz, S. H., \& Gotleib, A. (1980). Bystander anonymity and reaction to emergencies. Journal of Personality and Social Psychology, 39, 418-430.

Shotland, R. L., \& Straw, M. K. (1976). Bystander response to an assault: When a man attacks woman. Journal of Personality and Social Psychology, 34, 990-999. Smith, E. R., \& Mackie, D. M. (2007). Social Psychology, New York: Psychology Press.

Solomon, L. Z., Solomon, H., \& Stone, R. (1978). Helping as a function of number of bystanders and ambiguity of emergency. Personality and Social Psychology Bulletin, 4, 318-321.

Stürmer, S., Snyder, M., \& Omoto, A. M. (2005). Prosocial emotions and helping: The moderating role of Group Membership. Journal of Personality and Social Psychology, 88, 532-546.

Tatar, M., \& Horenczyk, G. (2003). Diversity-related burnout among teachers. Teaching and Teacher Education, 19, 397-408.

Toppo, G. (2007, August 1). How Bush education law has changed our schools. USA Today. Retrieved from http://www.usatoday.com/news/education/2007-01-07-no-child x.htm

UNESCO (2011, April 4). L'éducation pour l'inclusion: la voie pour l'avenir. Bureau International de l'Education, Genève. Retrieved from, http://www.ibe.unesco.org/fr/cie/48e-session-2008.html

Van den Bos, K., Müller, P. A., \& van Bussel, A. A. L. (2009). Helping to overcome intervention inertia in bystander's dilemmas: Behavioral disinhibition can improve the greater good. Journal of Experimental Social Psychology 45, 873-878. 
Aneta MECHI. Bystander in the Classroom? The Role of Feeling-of-Being-Concerned in the Perception of the Possibility to Help Unruly Behaving Pupils and its Relation with Social Cognitive Flexibility

PROBLEMS

OF EDUCATION

IN THE $21^{\text {st }}$ CENTURY

Volume 62,2014

Advised by Laima Railiene, University of Siauliai, Lithuania

73

Received: October 16, 2014

Accepted: November 26, 2014

Aneta Mechi

Ph.D. Student, Teacher Assistant, University of Geneva, 40 Boulevard du Pont d'Arve, 12011 Geneva 4.

E-mail: Aneta.Mechi@unige.ch

Website: http://cms.unige.ch/grife-ge/ 